\title{
Geological characteristics and accumulation mechanisms of the "continuous" tight gas reservoirs of the Xu2 Member in the middle- south transition region, Sichuan Basin, China
}

\author{
Zou Caineng ${ }^{1,2}$, Gong Yanjie ${ }^{1,2 *}$, Tao Shizhen ${ }^{1}$ and Liu Shaobo ${ }^{1,2}$ \\ ${ }^{1}$ Research Institute of Petroleum Exploration \& Development, PetroChina, Beijing 100083, China \\ ${ }^{2}$ State Key Laboratory of Enhanced Oil Recovery, Beijing 100083, China
}

(C) China University of Petroleum (Beijing) and Springer-Verlag Berlin Heidelberg 2013

\begin{abstract}
Continuous" tight gas reservoirs are those reservoirs which develop in widespread tight sandstones with a continuous distribution of natural gas. In this paper, we summarize the geological features of the source rocks and "continuous" tight gas reservoirs in the Xujiahe Formation of the middlesouth transition region, Sichuan Basin. The source rocks of the Xu1 Member and reservoir rocks of the Xu2 Member are thick (Xu1 Member: $40 \mathrm{~m}$, Xu2 Member: $120 \mathrm{~m}$ ) and are distributed continuously in this study area. The results of drilled wells show that the widespread sandstone reservoirs of the Xu2 Member are charged with natural gas. Therefore, the natural gas reservoirs of the Xu2 Member in the middle-south transition region are "continuous" tight gas reservoirs. The accumulation of "continuous" tight gas reservoirs is controlled by an adequate driving force of the pressure differences between source rocks and reservoirs, which is demonstrated by a "one-dimensional" physical simulation experiment. In this simulation, the natural gas of "continuous" tight gas reservoirs moves forward with no preferential petroleum migration pathways (PPMP), and the natural gas saturation of "continuous" tight gas reservoirs is higher than that of conventional reservoirs.
\end{abstract}

Key words: Geological characteristics, accumulation mechanism, "continuous" tight gas reservoir, Xu2 Member, middle-south transition region, Sichuan Basin

\section{Introduction}

"Continuous" tight gas reservoirs are those reservoirs which develop in widespread tight sandstones with a continuous distribution of natural gas (Gautier et al, 1995; Schmoker, 1999; 2002; 2005). The global resource of "continuous" tight gas reservoirs is great, meaning that they have huge exploration potential (Gautier et al, 1995; Schmoker, 1999; 2002; 2005; Klett and Charpentier, 2003; Klett and Schmoker, 2004; Cook, 2004; Crovelli, 2004). The American production of "continuous" tight gas reservoirs in 2007 reaches $0.5 \times 10^{12} \mathrm{~m}^{3}$, accounting for $1 / 6$ of the overall natural gas production (Pollastro, 2007). Therefore, it is important to enhance the research into exploration and development of "continuous" tight gas reservoirs. These reservoirs are characterized by the following aspects: 1) the source rocks primarily contain type III kerogen and are distributed continuously; 2) the reservoir rocks are distributed continuously and have low porosity and permeability; 3 ) these

*Corresponding author. email: gongyanjie2008@petrochina.com.cn Received September 2, 2011 reservoirs commonly consist of large volumes of sandstones pervasively charged with gas; 4) the sources rocks are close to sandstones and most of these reservoirs are not directly dependent on the buoyancy of gas in water for their existence.

There are rich natural gas resources in the Xu2 Member in the middle-south transition region, Sichuan Basin, China. Several big natural gas fields such as Hechuan, Tongnan and Anyue whose reserves are all over $0.1 \times 10^{12} \mathrm{~m}^{3}$ have been found in recent years. The exploration results show that each drilled well in the Xu2 Member in the study area is capable of producing at least some gas, but the production characteristics of the drilled wells can vary significantly $\left((0.001-200) \times 10^{3}\right.$ $\mathrm{m}^{3} / \mathrm{d}$ ). Many geologists have carried out their studies of the Xujiahe Formation in this area (Zhang and Zhang, 2002; Zou et al, 2008; Yang et al, 2006; Guo et al, 1996; Deng, 1992). In summary their results show: 1) the lower source rocks in the Xu1 Member are close to the upper sandstones in the Xu2 Member; 2) there are large volumes of sandstones pervasively charged with gas and which cannot be represented in terms of individual, countable pools delineated by down-dip water contacts. All the characteristics are different from those of conventional natural gas pools. 
There are still problems: Can the natural gas reservoirs of the Xu2 Member be classified as "continuous" tight gas reservoirs? What are the geological characteristics of the natural gas reservoirs in the Xu2 Member? What is the driving force for the accumulation of "continuous" tight gas reservoirs; buoyancy or pressure?

In this paper, we studied comprehensively the geological characteristics of the source rocks and sandstones of "continuous" tight gas reservoirs in the Xu2 Member and the physical simulation of "continuous" tight gas reservoirs was carried out in the Key Laboratory of Petroleum Accumulation of CNPC to analyze the accumulation mechanism.

\section{Geological setting}

The Sichuan Basin is the fourth largest basin in China, locating in the eastern part of Sichuan Province near Chongqing City. It is a very important petroliferous basin (Long et al, 2011; Zhang et al, 2012). It is bordered by the Micang Mountains and Daba Mountains to the north, the Daliang Mountains to the south, the Longmen Mountains and Qionglai Mountains to the west and the Qiyao Mountains to the east, with a total area of about $180 \times 10^{3} \mathrm{~km}^{2}$. The Sichuan Basin is a large sedimentary basin surrounded by folds and faults (Luo and Tong, 1989; Wang et al, 2002). It can be divided into six tectonic units (Fig. 1): foreland depression area in the west (I), flat fold area in the middle (II), thrust fold area in the north (III), steep structure area in the east (IV), uplift in the west and south (V), less steep fold area in the south (VI). Our study area is the middle-south transition area with a total area of $17.5 \times 10^{3} \mathrm{~km}^{2}$, which is flatly folded (Fig. 1), and contains Suining, Moxi, Longnüsi, Anyue, Hechuan, Tongnan and Hebaochang natural gas fields. In the geologic history, this area went through the following tectonic evolution: Caledonian and ancient Indosinian uplift, late Indosinian and Yanshan foreland slope, and the Himalayan tectonic uplift (Guo et al, 1996; Deng, 1992).

The Upper Triassic Xujiahe Formation was formed after the early Indosinian movement (Fig. 2). It is primarily a set of continental foreland basin system with coal. It can be divided into six members from bottom to top (Xu1, Xu2, Xu3, $\mathrm{Xu} 4, \mathrm{Xu} 5$, and Xu6). The Xu1, Xu3, and Xu5 members are primarily dark mudstones and coals. The $\mathrm{Xu} 2, \mathrm{Xu} 4$, and $\mathrm{Xu} 6$ members are primarily sublitharenite, feldspathic litharenite and litharenite (Zhao et al, 2008; Zhang et al, 2010; Wang et al, 1997). The Lower Jurassic Zhenzhuchong Formation overlies the Xujiahe Formation with a parallel unconformity

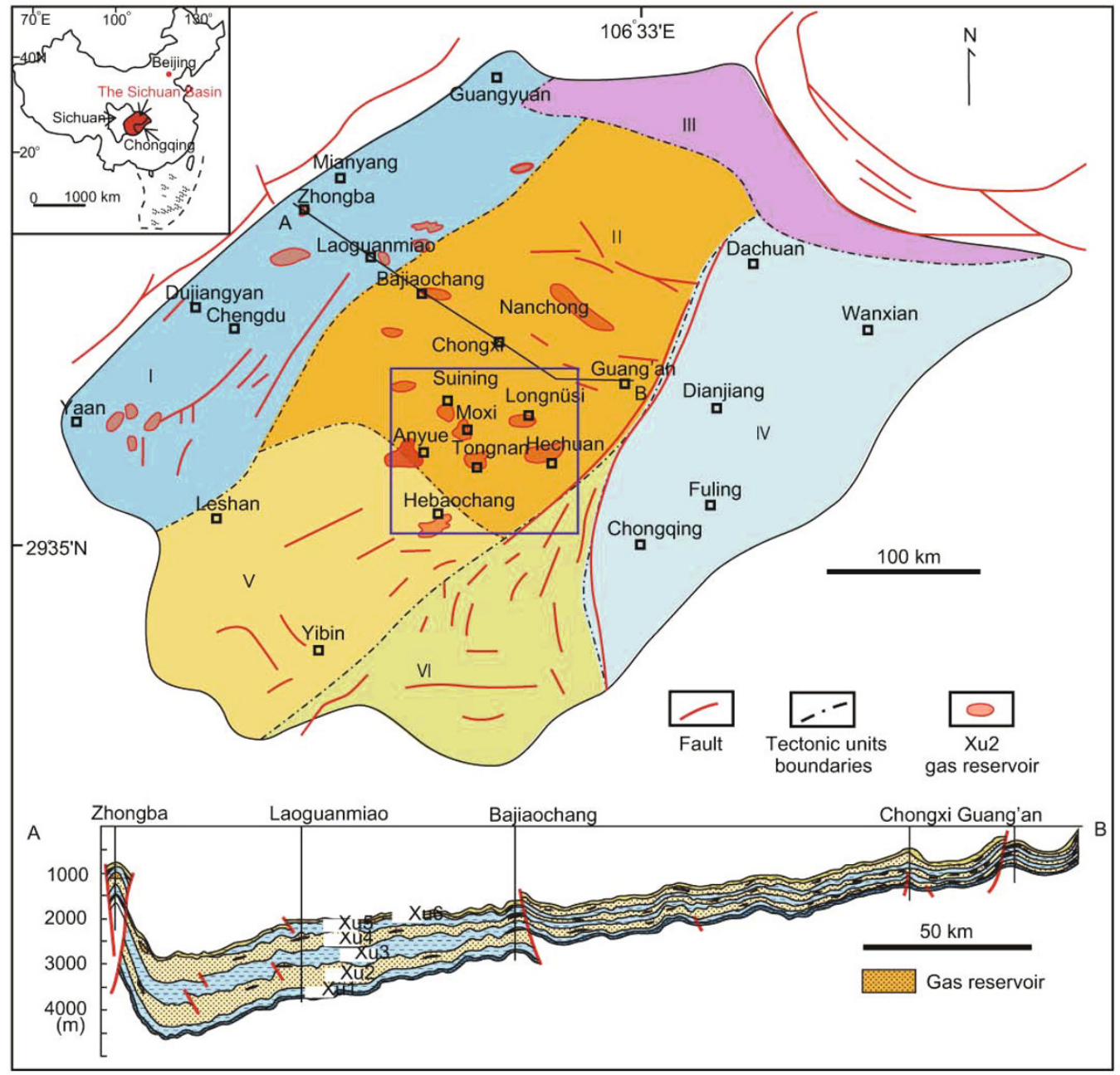

Fig. 1 Location map showing the sub-units of the Sichuan Basin. The area in the black frame is the middle-south transition region and the cross section $\mathrm{AB}$ shows the location of the Xu2 Member in the Xujiahe Formation 
while the Xujiahe Formation overlies the Middle Triassic Leikoupo Formation also with a parallel unconformity (Fig. 2).

The Sichuan Basin is rich in natural gas resources. Several natural gas fields in the Xu2 Member have been discovered since 1950s (Fig. 2). Reserves of Hechuan, Tongnan and Anyue natural gas fields are all over $0.1 \times 10^{12} \mathrm{~m}^{3}$.

\begin{tabular}{|c|c|c|}
\hline System & Series & Formation \\
\hline \multicolumn{3}{|c|}{ Quaternary Quaternary } \\
\hline \multirow{2}{*}{ Tertiary } & \multirow{2}{*}{ Lower } & Lushan \\
\hline & & Mingshan \\
\hline \multirow{3}{*}{ Cretaceous } & \multirow{2}{*}{ Upper } & Guankou \\
\hline & & Jiaguan \\
\hline & \begin{tabular}{|l|} 
Lower \\
\end{tabular} & Jiading \\
\hline \multirow{4}{*}{ Jurassic } & First & $\begin{array}{l}\text { Penglaizhen } \\
\text { Suining }\end{array}$ \\
\hline & Second & Shaximiao \\
\hline & \multirow{2}{*}{ Third } & Lianggaoshan \\
\hline & & Ziliujing \\
\hline \multirow{4}{*}{ Triassic } & First & Xujiahe \\
\hline & Second & Leikoupo \\
\hline & \multirow{2}{*}{ Third } & Jialingjiang \\
\hline & & Feixianguan \\
\hline \multirow{5}{*}{ Permian } & \multirow{2}{*}{ Upper } & Changxing \\
\hline & & Longtan \\
\hline & \multirow{3}{*}{ Lower } & Maokou \\
\hline & & Qixia \\
\hline & & Liangshan \\
\hline \multirow{2}{*}{ rboniferc } & Upper & Huanglong \\
\hline & Lower & Hezhou \\
\hline \multirow{4}{*}{ Silurian } & First & Huixingshao \\
\hline & Second & Hanjiadian \\
\hline & \multirow{2}{*}{ Third } & Xiaoheba \\
\hline & & Longmaxi \\
\hline \multirow{7}{*}{ Ordovician } & \multirow[t]{2}{*}{ First } & Wufeng \\
\hline & & Linxiang \\
\hline & \multirow{2}{*}{ Second } & Baota \\
\hline & & Shizipu \\
\hline & \multirow{3}{*}{ Third } & Dawan \\
\hline & & Honghuayuan \\
\hline & & Tongzi \\
\hline \multirow{8}{*}{ Cambrian } & \multirow{2}{*}{ First } & Maotian \\
\hline & & Houba \\
\hline & \multirow{3}{*}{ Second } & Pingjing \\
\hline & & Maoping \\
\hline & & Gaotai \\
\hline & \multirow{3}{*}{ Third } & Longwangmiac \\
\hline & & Lianglangpt \\
\hline & & Shizhusi \\
\hline \multirow{4}{*}{ Sinian } & & Dengying \\
\hline & upper & Labagang \\
\hline & Lower & Nantuo \\
\hline & & Pengtuo \\
\hline
\end{tabular}

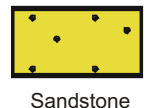

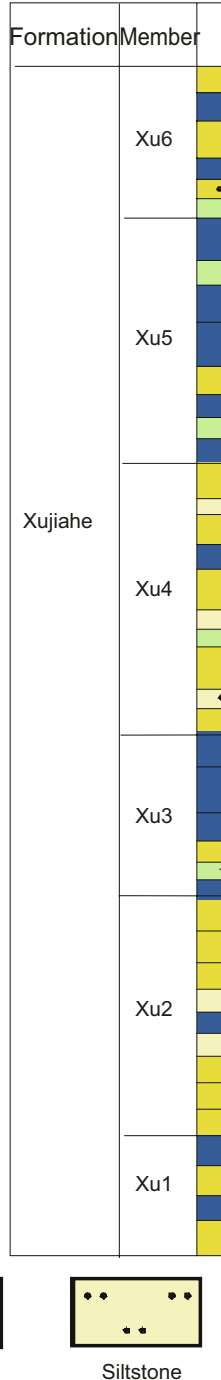
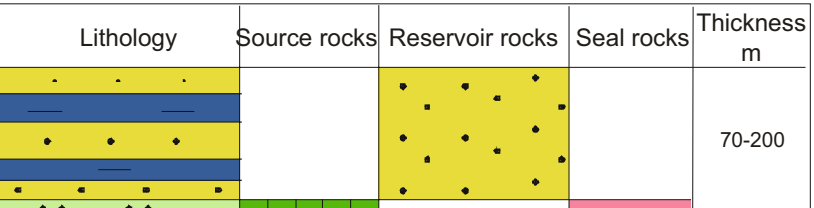

\begin{tabular}{l|c}
\hline & $m$ \\
\hline & $70-200$
\end{tabular}
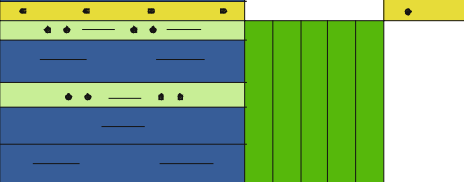

$\cdot \cdot \cdot \cdot+\cdot$
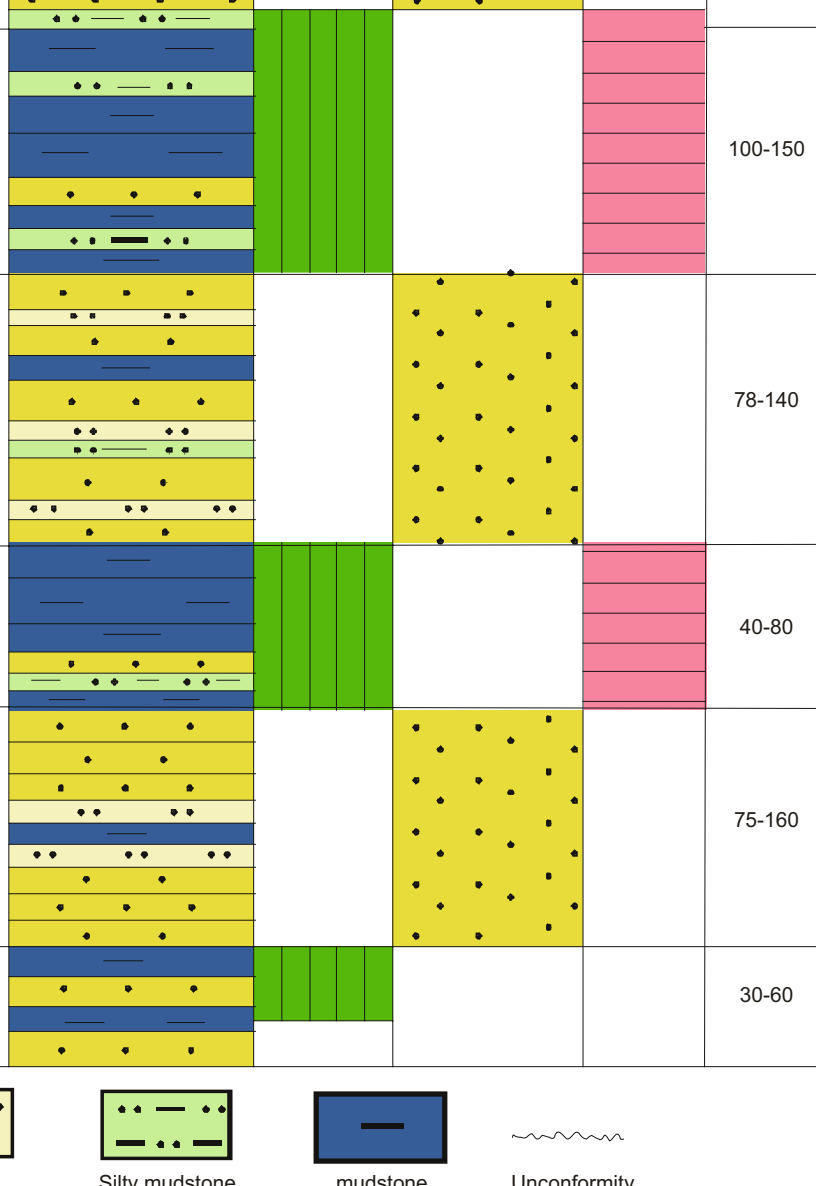

Unconformity

Fig. 2 Stratigraphic column in the Sichuan Basin

\section{Distribution characteristics of "continuous" tight gas reservoirs}

We selected a two-dimensional seismic exploration area (nearly 3,000 $\mathrm{km}^{2}$ ) which covers the Tongnan, Hechuan, north of Anyue, east of Hebaochang fields and contains 79 drilled wells, compiled a natural gas saturation map using the logging data of drilled wells in this area, and corrected this map with the thickness of sandstone reservoir obtained by two-dimensional seismic data. The results show that the widespread sandstones of the $\mathrm{Xu} 2$ Member are charged with natural gas. The natural gas production is closed to the natural gas saturation in the drilled wells. The natural gas saturation of drilled wells in Hechuan and Tongnan areas is up to $70 \%$ (Fig. 3).

We also obtained the natural gas saturation of drilled wells from the well log interpretation, and compiled the well section
AB (17 drilled wells across the Anyue, Tongnan and Hechuan natural gas fields) of natural gas saturation in "continuous" tight gas reservoirs of the $\mathrm{Xu} 2 \mathrm{Member}$. The results show that the natural gas saturation is above $35 \%$, which indicates that the widespread sandstones of the Xu2 Member are charged with natural gas (Fig. 4).

\section{Source rocks}

\subsection{Continuous distribution}

The dark mudstones and coals of the Xu1 Member and $\mathrm{Xu} 2$ Member are source rocks for "continuous" tight gas reservoirs in the Xu2 Member. The source rocks are distributed continuously in this study area. The thickness of the mudstones in the Xu1 Member increases from southeast to northwest, and the average thickness is about $40 \mathrm{~m}$. The thickness in the Suining, Lujiaba, and Hebaochang areas is 


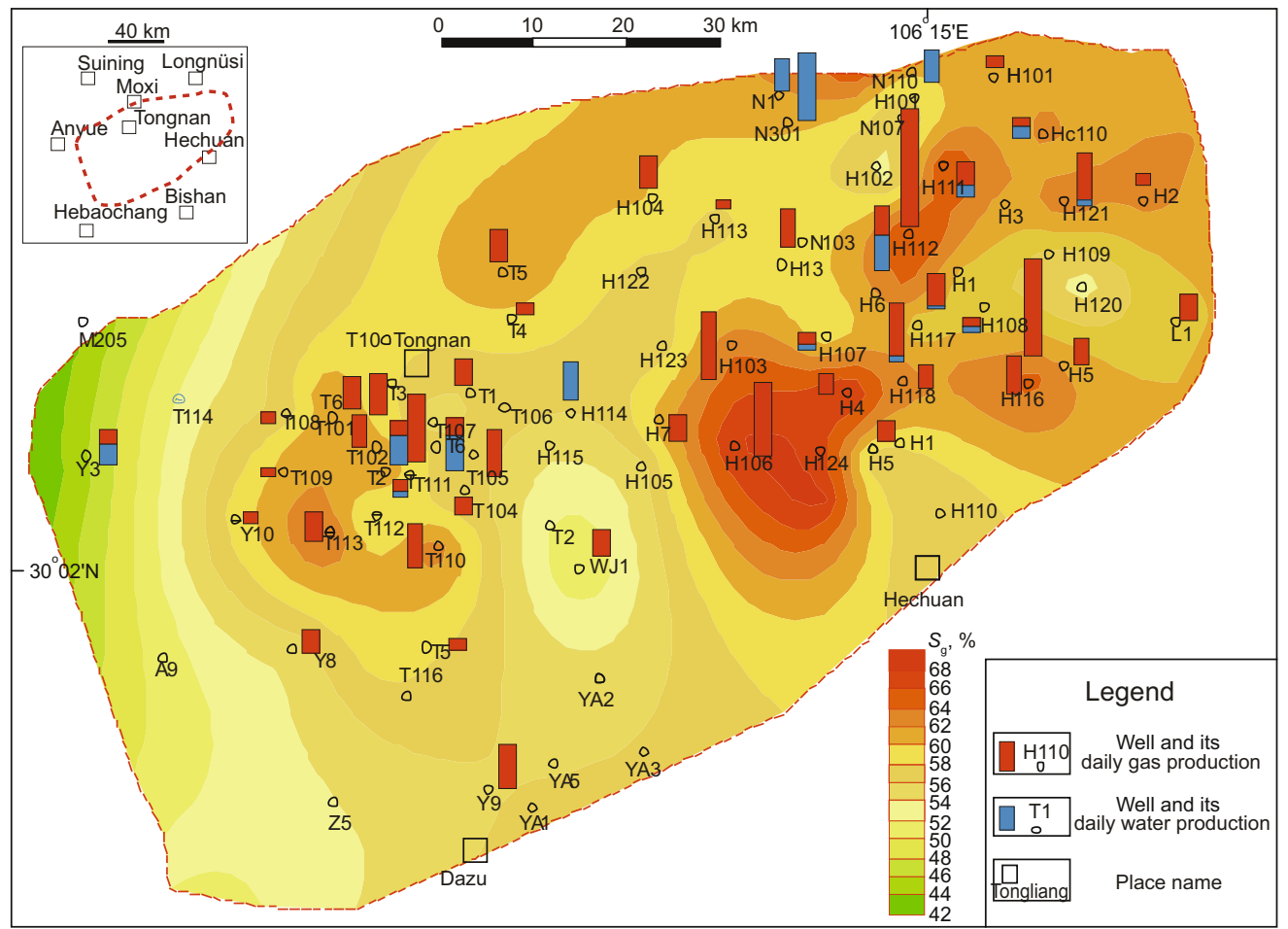

Fig. 3 Distribution map of the natural gas saturation of "continuous" tight gas reservoirs in the Xu2 Member in the Anyue-Hechuan area

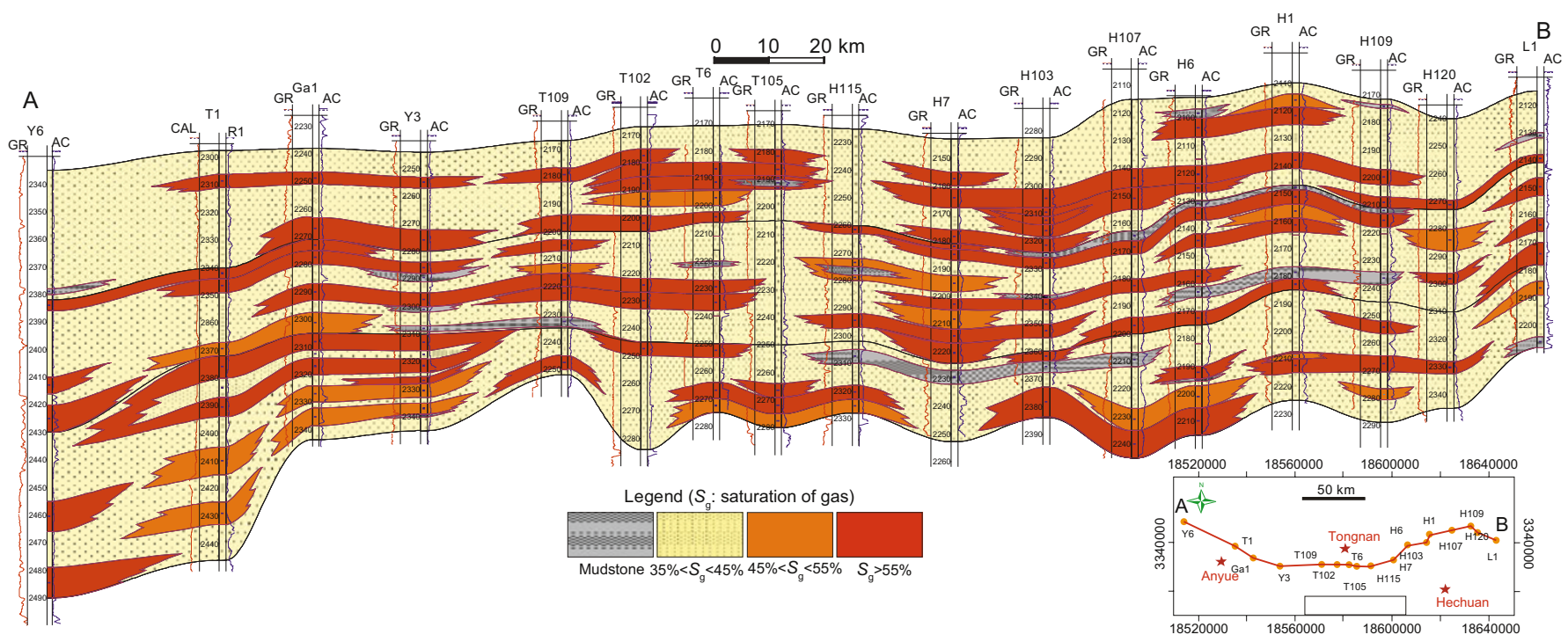

Fig. 4 Section $\mathrm{AB}$ of the natural gas saturation of "continuous" tight gas reservoirs in the Xu2 Member. The red layers' natural gas saturations are greater than $55 \%$ and the red layers can produce industrial natural gas

the largest and the average thickness is more than $50 \mathrm{~m}$. In the Moxi area, the average thickness is about $40 \mathrm{~m}$ and there is no mudstone in Hechuan, Tongnan areas because erosion occurred in the Late Cretaceous (Fig. 5). The thickness of the coals in the Xu1 Member increases from center to the edges, and the average thickness is about $2.5 \mathrm{~m}$. The thickness in Suining, Sichuan, Anyue and Hebaochang areas is the largest and the average thickness is more than $3 \mathrm{~m}$. In the Hechuan and Tongnan areas, the average thickness is about 1-2 m (Fig. 6). A set of mudstones in the Xu2 Member, whose sedimentary facies are underwater distributary interchannel of braided river delta front, develop in the whole study area, and the average thickness is about $15 \mathrm{~m}$. The mudstone thickness in the Hechuan, Tongnan and Anyue areas is the highest and the average thickness is more than $25 \mathrm{~m}$ (Fig. 7).

\subsection{High natural gas generation intensity}

Peak gas generation is occurring now because the maturity of the source rocks ranges from $1.0 \%$ to $1.5 \%$ (Huang et al, 2004) which means the organic matter can produce a large amount of natural gas. The high natural gas generation intensity (average $1,000 \times 10^{6} \mathrm{~m}^{3} / \mathrm{km}^{2}$ ) (Fig. 8) guarantees the formation of "continuous" tight gas reservoirs of the Xu2 Member in the study area.

The source rocks primarily contain of type III kerogen (Wang et al, 1997; 2010), and are distributed continuously in 


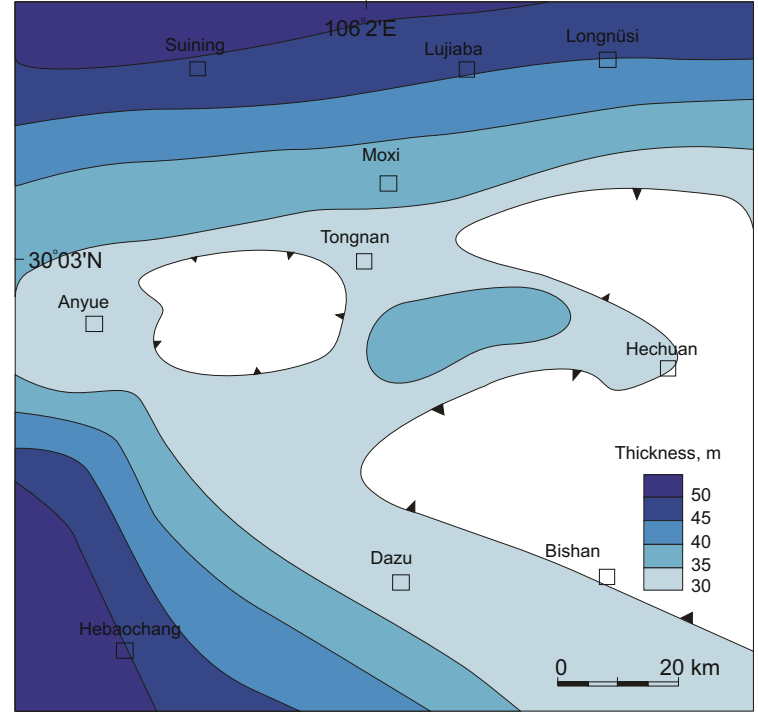

Fig. 5 Map of the thickness of mudstones of the Xu1 Member in the study area

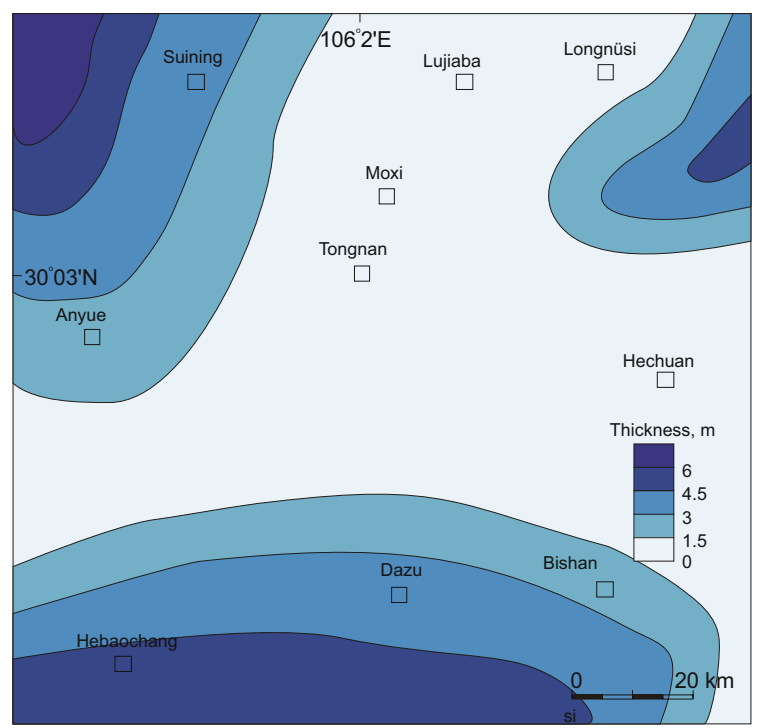

Fig. 6 Map of the thickness of coals of the Xu1 Member in the study area

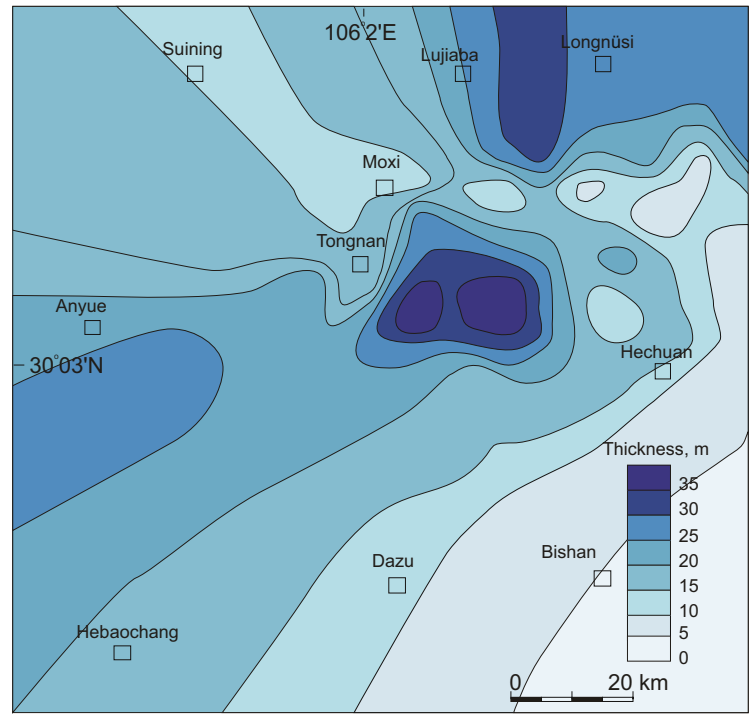

Fig. 7 Map of the thickness of mudstones of the Xu2 Member in the study area

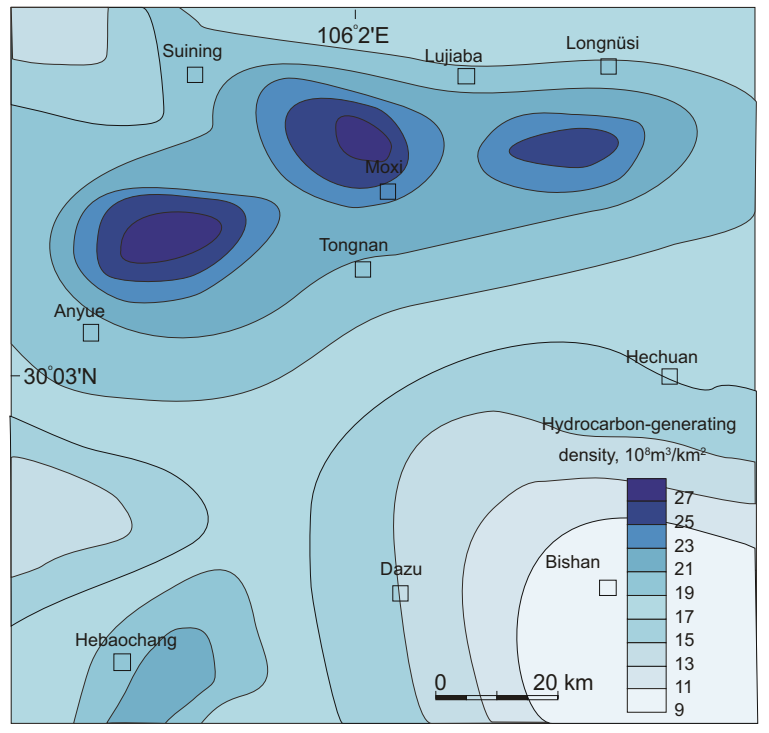

Fig. 8 Map of the gas intensity of source rocks in the study area. The overall average intensity is $1,000 \times 10^{6} \mathrm{~m}^{3} / \mathrm{km}^{2}$; the average intensity in Suining, Moxi, and Longnüsi natural gas fields is above $2,000 \times 10^{6} \mathrm{~m}^{3} / \mathrm{km}^{2}$; the average intensity in Hechuan-Tongnan region is also above $1,200 \times 10^{6}$ $\mathrm{m}^{3} / \mathrm{km}^{2}$

this study area. The source rocks of the $\mathrm{Xu} 2$ Member have a widespread distribution, high thickness, and high natural gas generation intensity. Therefore, they can provide adequate natural gas supply for the formation of "continuous" tight gas reservoirs in the whole study area.

\section{Reservoir rocks}

\subsection{Low porosity and permeability and volcanic debris dissolution pores form the main pore space}

The sediments of the Xu2 Member in the study area belong to the braided delta front in a shallow lake environment ( $Z$ hu et al, 2009; Li et al, 2003). The micro sedimentary facies are primarily underwater distributary channel, mouth bar and underwater distributary interchannel. The reservoir rocks are large sets of middle-fine sandstones, and some siltstones which are primarily sublitharenite, feldspathic litharenite and litharenite (Fig. 9). The average porosity of reservoir rocks is $5 \%$ to $6 \%$, the logging Darcy permeability is less than $0.1 \mathrm{mD}$, and most of the pore diameters are less than $1 \mu \mathrm{m}$ (Table 1).

The content of volcanic debris and other flexible ductile particles in the sandstone reservoirs is high but early carbonate cements are not observed (Table 2). The diagenesis is strong, including compaction and silica, calcite and illite cementation. Strong compaction caused close contact of sandstone particles, deformation of ductile particles and breakdown of rigid particles (Fig. 10(a), (b)). Silica cementation, calcite cementation and illite cementation (Fig. 10(c), (d)) were also key factors for the low porosity and permeability of reservoirs. Silica cement is always in the form of authigenic quartz and the content is generally $0.5 \%$ to $3.5 \%$ or higher, up to $16 \%$. Occurrences of silica cement can be the overgrowth of quartz grains and microcrystalline quartz. 


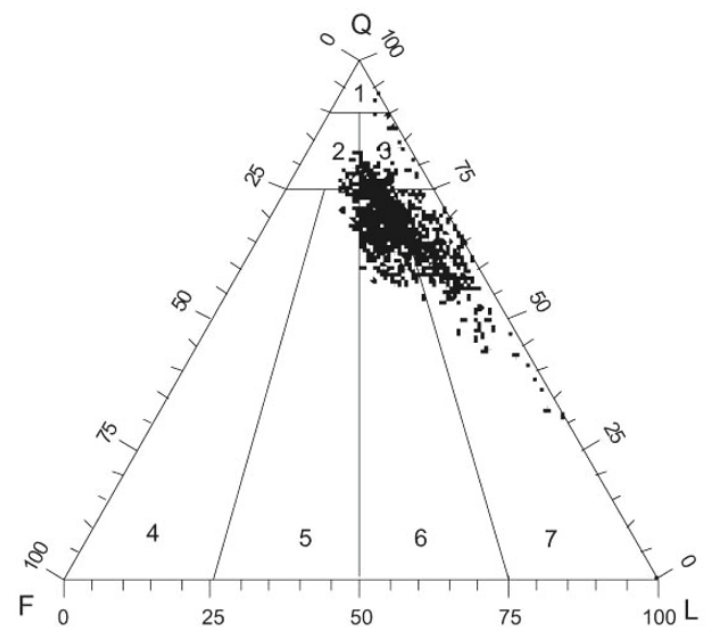

Fig. 9 Sandstone classification ternary diagram. There are 956 samples of the Xu2 Member in the graph. 1=Quartzarenite, 2=Subarkose, $3=$ Sublitharenite, $4=$ Arkose, $5=$ Lithic arkose, $6=$ Feldspathic litharenite, $7=$ Litharenite
Calcite cement is formed in the middle-late A2 diagenesis and later than the formation of the membrane of chlorite.

Strong compaction and cementation caused the low porosity and permeability of the reservoir rocks, while the late dissolution, especially the dissolution occurring in volcanic debris effectively protected the pores and improved the porosity and permeability of the reservoirs (Fig. 11), which is helpful for the accumulation of "continuous" tight gas reservoirs. This secondary porosity in volcanic debris is the main pore space in the reservoir rocks.

The reservoir rocks of the Xu2 Member have low porosity, low permeability and low saturation of free water (Table 3), which will result in poor potential energy exchange between lower and upper natural gas volumes. The natural gas reservoirs are thin (3-8 $\mathrm{m}$ ), so the buoyancy is less than the capillary pressure (Table 4), meaning that the buoyancy cannot provide enough driving force for gas migration.

Table 1 Porosity and permeability of reservoir rocks in the Xu2 Member in the study area

\begin{tabular}{|c|c|c|c|c|c|c|c|c|}
\hline \multirow{2}{*}{ Member } & \multicolumn{4}{|c|}{ Porosity, \% } & \multicolumn{4}{|c|}{ Permeability, mD } \\
\hline & Average & $\operatorname{Max}$ & Min & Number of samples & Average & $\operatorname{Max}$ & Min & Number of samples \\
\hline $\mathrm{Xu} 2$ & 6.21 & 17.68 & 0.65 & 1310 & 0.07 & 1.8 & 0.002 & 462 \\
\hline
\end{tabular}

Table 2 Debris of the Xu2 Member in the study area

\begin{tabular}{|c|c|c|c|c|c|c|c|c|c|c|c|}
\hline & \multirow{3}{*}{ Quartz, \% } & \multirow{3}{*}{ Feldspar, \% } & \multicolumn{8}{|c|}{ Rock debris, $\%$} & \multirow{3}{*}{ Matrix, $\%$} \\
\hline & & & \multirow{2}{*}{$\begin{array}{c}\begin{array}{l}\text { Volcanic } \\
\text { rocks }\end{array} \\
\end{array}$} & \multicolumn{3}{|c|}{ Metamorphic rocks } & \multicolumn{4}{|c|}{ Sedimentary rocks } & \\
\hline & & & & Quartzite & Phyllite & Schist & Mudstone & Sandstone & Chert & Mica & \\
\hline Content & $24-86$ & $0.5-18$ & $5-56$ & $1-35$ & $0.5-1.5$ & $0-1$ & $0-6$ & $0-8$ & $0-5$ & $0-2$ & $0.5-5$ \\
\hline Average & 58.6 & 8.7 & 20.6 & 6.2 & 1.4 & 0.1 & 1.3 & 1.2 & 1.7 & 0.2 & 1.5 \\
\hline
\end{tabular}
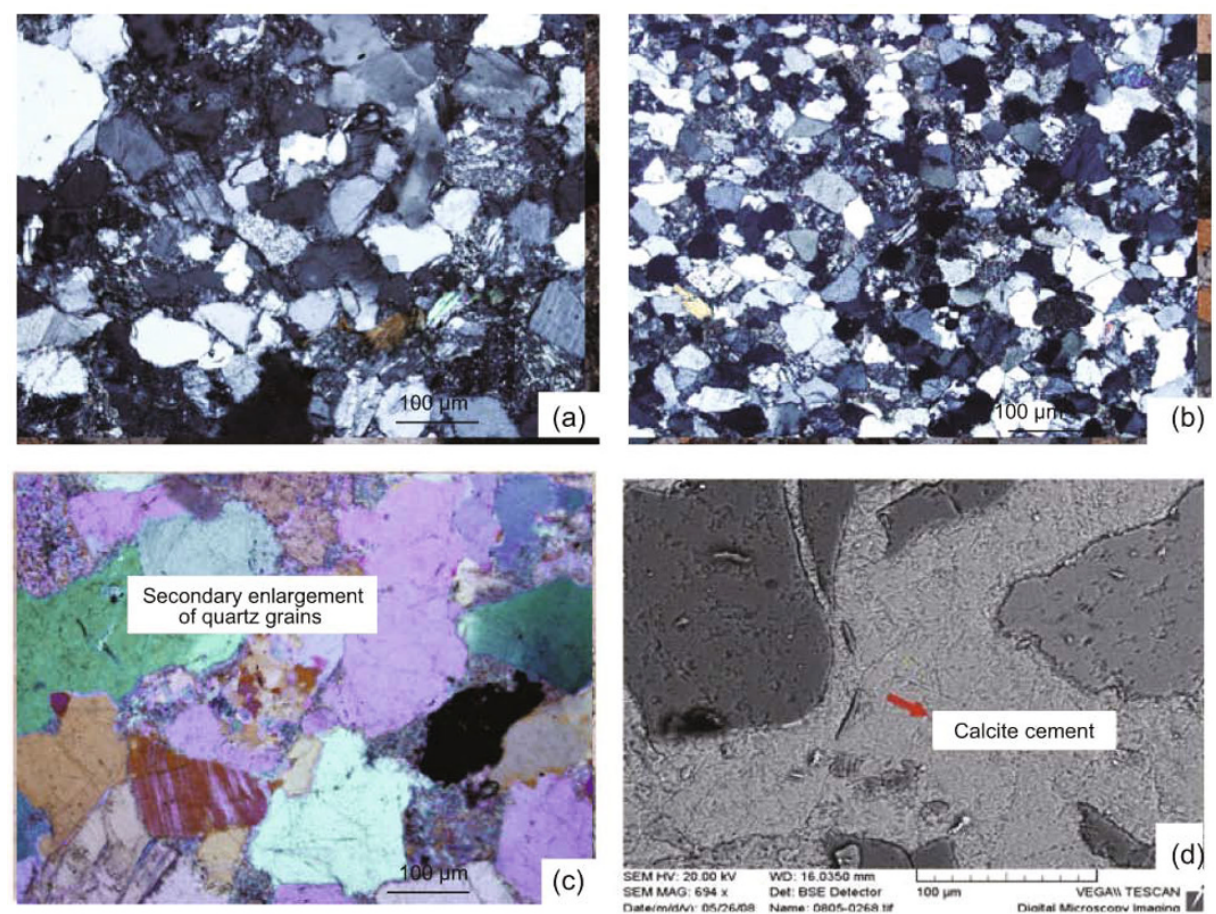

Fig. 10 Strong diagenesis of the Xu2 Member in the study area. (a): H6, $2159.29 \mathrm{~m}$, Xu2, fine-medium grained lithic sandstone; (b): T6, 2013.35 m, Xu4, medium-coarse-grained lithic sandstone; (c): T102, $2102.8 \mathrm{~m}$, medium grain lithic sandstone, euhedral quartz filling the dissolution pores of chlorite; (d): H1, $2083.2 \mathrm{~m}$, crystalline calcite cement filling in the form of plaque, Xu2, medium-grained lithic sandstone 

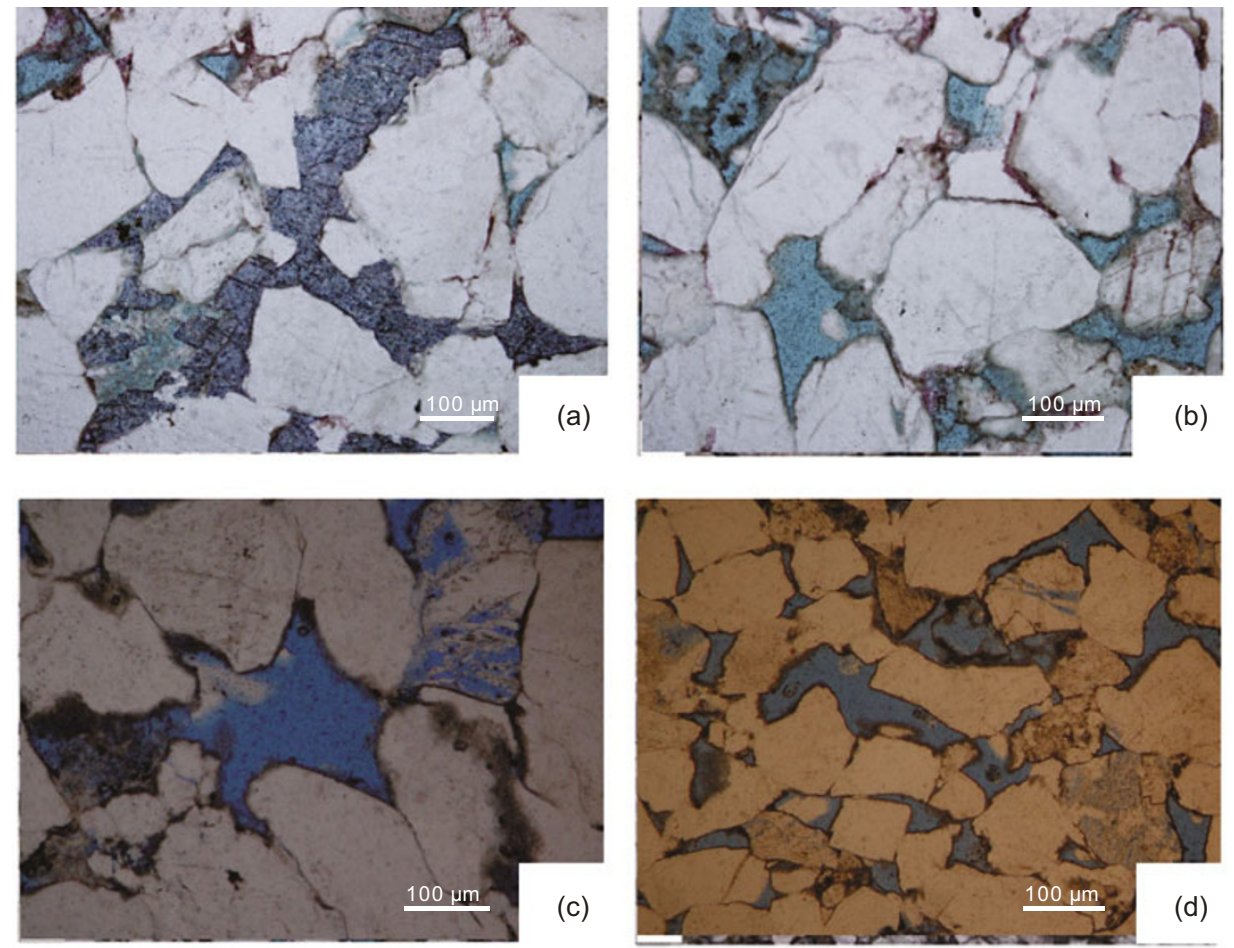

Fig. 11 Dissolution pores of the Xu2 Member in the study area. (a): H5, $2014 \mathrm{~m}, \mathrm{Xu} 2$, medium-grained feldspathic litharenite; (b): H6, 2022 m, Xu2, coarse-grained litharenite, (c): T102, 2038 m, Xu2, coarsegrained litharenite; (d): T107, $2010 \mathrm{~m}, \mathrm{Xu} 2$, medium-grained litharenite

Table 3 Water types of reservoir rocks in the Xu2 Member in the study area

\begin{tabular}{ccccc}
\hline Porosity, \% & Proportion, \% & Permeability, $\mathrm{mD}$ & Water type & $\begin{array}{c}\text { Single well } \\
\text { water production, } \mathrm{m}^{3}\end{array}$ \\
\hline$<8$ & 69 & $>1.1$ & Adsorbed water & $<5$ \\
$8-10$ & 22 & $0.35-1.1$ & Bound water & $5-15$ \\
$>10$ & 9 & $<0.35$ & Free water & $>15$ \\
\hline
\end{tabular}

\subsection{Thick and continuous distribution}

As mentioned above, the micro sedimentary facies of the Xu2 Member are primarily underwater distributary channel and mouth bar, and some underwater distributary interchannel. Large trough cross bedding (Fig. 12(a)), scour filling structure (Fig. 12(b)) and large sets of thick coarse grain sized sandstones with a bell-shaped log gamma curve always develop in underwater distributary channel. Small trough cross bedding (Fig. 12(c)), wormhole construction (Fig. 12(d)), and small sized sandstones with a funnel-shaped gamma curve and good sorting (Fig. 13) develop in delta mouth bars.

Because the braided channels frequently changed during deposition, sand lens formed by the multi-channel deposits overlapped vertically, developing sandstone layers of $10 \mathrm{~m}$ or more (Fig. 14). The sandstone layers are distributed continuously in the study area, and are thick (Fig. 15).

The reservoir rocks of the $\mathrm{Xu} 2 \mathrm{Member}$ are distributed continuously in the study area, which is favorable for the formation of "continuous" tight gas reservoirs.

\section{The relationship between source rocks and reservoir rocks}

\subsection{Sources rocks are close to reservoir rocks}

Braided delta front distributary channels develop generally in the Xu2 Member in the study area. Channels changed frequently during the deposition, resulting in interspersed distribution of large sets of sandstones and mudstones (Fig. 16), which is also advantageous for the formation of "continuous" tight gas reservoirs. Outcrops of the Xu2 Member in Huangshiban area of the Sichuan Basin show that the large sets of sandstones (thicknesses are mostly $2 \mathrm{~m}$ ) and coals (thicknesses are mostly $0.5 \mathrm{~m}$ ) are interspersed because the braided rivers changed frequently. Abandoned river sections formed oxbow lakes, in which were deposited a set of coal beds and a mudstone cap. After that, the channel changed again and formed a braided river, eroded the mudstone cap, and the channel sandstones covered the coal bed directly. In planar view, source rocks and reservoir rocks are distributed 
Table 4 Comparison of the capillary pressure and buoyancy of reservoir rocks in the Xu2 Member in the study area

\begin{tabular}{cccccc}
\hline Well & Top depth, $\mathrm{m}$ & Gas reservoir thickness, $\mathrm{m}$ & Buoyancy, Pa & $\begin{array}{c}\text { Capillary pressure in mercury } \\
\text { test, MPa }\end{array}$ & $\begin{array}{c}\text { Buoyancy is less than the } \\
\text { capillary pressure }\end{array}$ \\
\hline H6 & 2195.3 & 8.1 & $81 \times 10^{3}$ & $0.29 \times 10^{6}$ & Yes \\
H6 & 2139 & 3 & $30 \times 10^{3}$ & $1.08 \times 10^{6}$ & Yes \\
H7 & 2191.2 & 6 & $60 \times 10^{3}$ & $0.19 \times 10^{6}$ & Yes \\
H7 & 2169.8 & 4.6 & $46 \times 10^{3}$ & $0.43 \times 10^{6}$ & Yes \\
T104 & 2205 & 8.6 & $86 \times 10^{3}$ & $0.31 \times 10^{6}$ & Yes \\
T107 & 2250 & 7.2 & $72 \times 10^{3}$ & $0.2 \times 10^{6}$ & Yes \\
T107 & 2261 & 7 & $70 \times 10^{3}$ & $0.23 \times 10^{6}$ & Yes \\
T108 & 2235 & 3 & $30 \times 10^{3}$ & $0.4 \times 10^{6}$ & Yes \\
T111 & 2225.5 & 8.5 & $85 \times 10^{3}$ & $0.42 \times 10^{6}$ & Yes \\
\hline
\end{tabular}
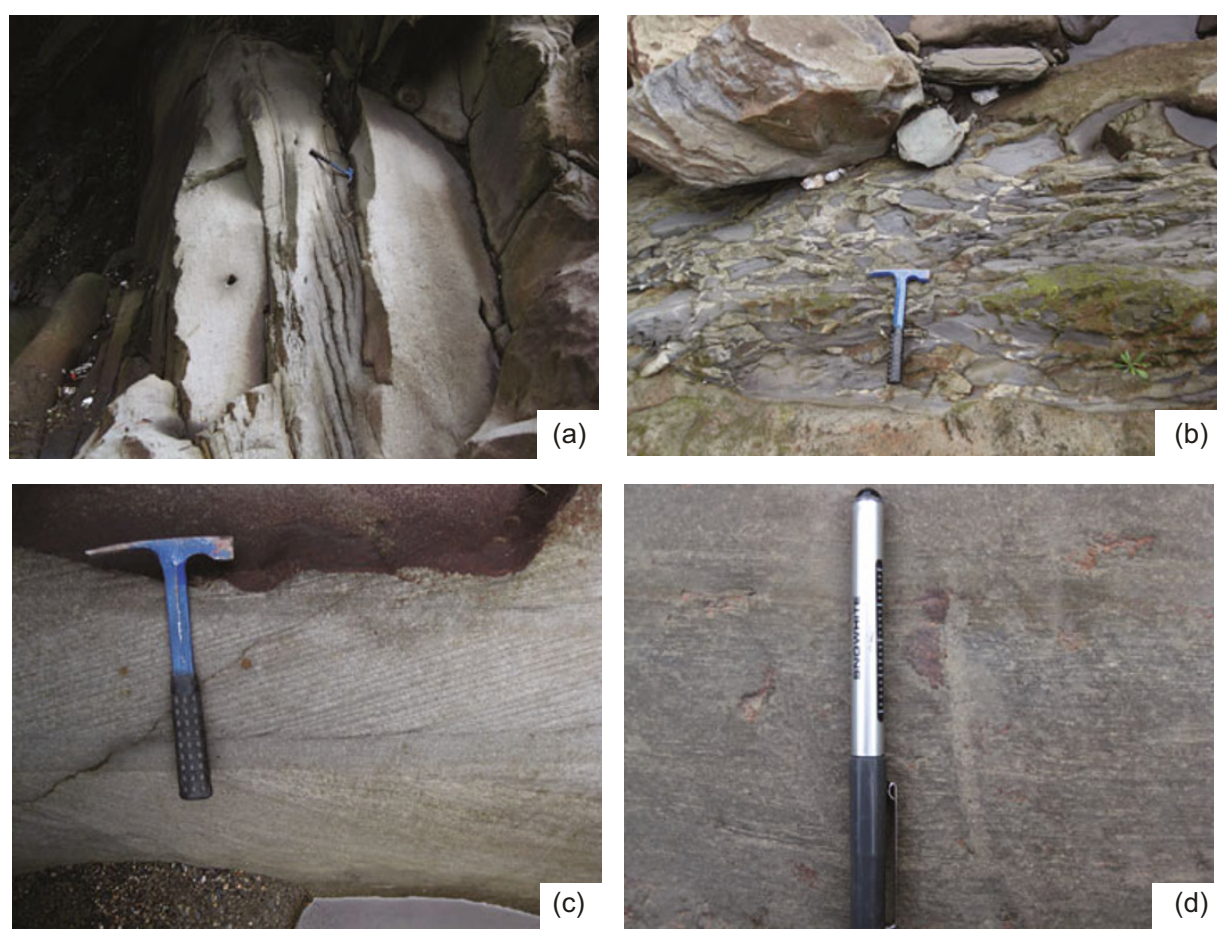

Fig. 12 Sedimentary facies of the Xu2 Member in the study area

continuously in the study area. In section, the source rocks contact closely with the reservoir rocks. Therefore, the distribution relationship between source rocks and reservoir rocks is also helpful for the formation of "continuous" tight gas reservoirs.

\subsection{Enough pressure in source rocks and reservoir rocks}

The hydrocarbon generation and differential compaction during burial process of the Xujiahe Formation in the middlesouth transition region resulted in enough pressure in source rocks and reservoir rocks to control the accumulation of "continuous" tight gas reservoirs (Zou et al, 2009a; 2009b). The main accumulation period of "continuous" tight gas reservoirs in the Xu2 Member is Cretaceous (Wang et al, 2012). The pressures in the Xu1 Member and Xu2 Member (Fig. 17) in the study area are all greater than $2 \mathrm{MPa}$, and most of pressures are greater than $3 \mathrm{MPa}$. The mercury displacement pressure when the mercury content is $50 \%$ in the experiment corresponds to the expulsion pressure (Wang et al, 2000). According to the study of Southwest Oil and Gas Field Company of PetroChina, the average pressure value of mercury in the experiment in Hechuan and Tongnan areas is 2 $\mathrm{MPa}$, which indicates that the accumulation of "continuous" natural gas pools is controlled by an adequate driving force between the pressures in source rocks and reservoirs.

\section{Physical simulation of "continuous" natural gas pool}

Two sets of "one-dimensional" physical simulation experiments were designed in order to further explain that the accumulation of "continuous" tight gas reservoirs is controlled by the adequate driving force between pressures in source rocks and reservoirs rather than buoyancy which controls the accumulation of conventional natural gas pools. 


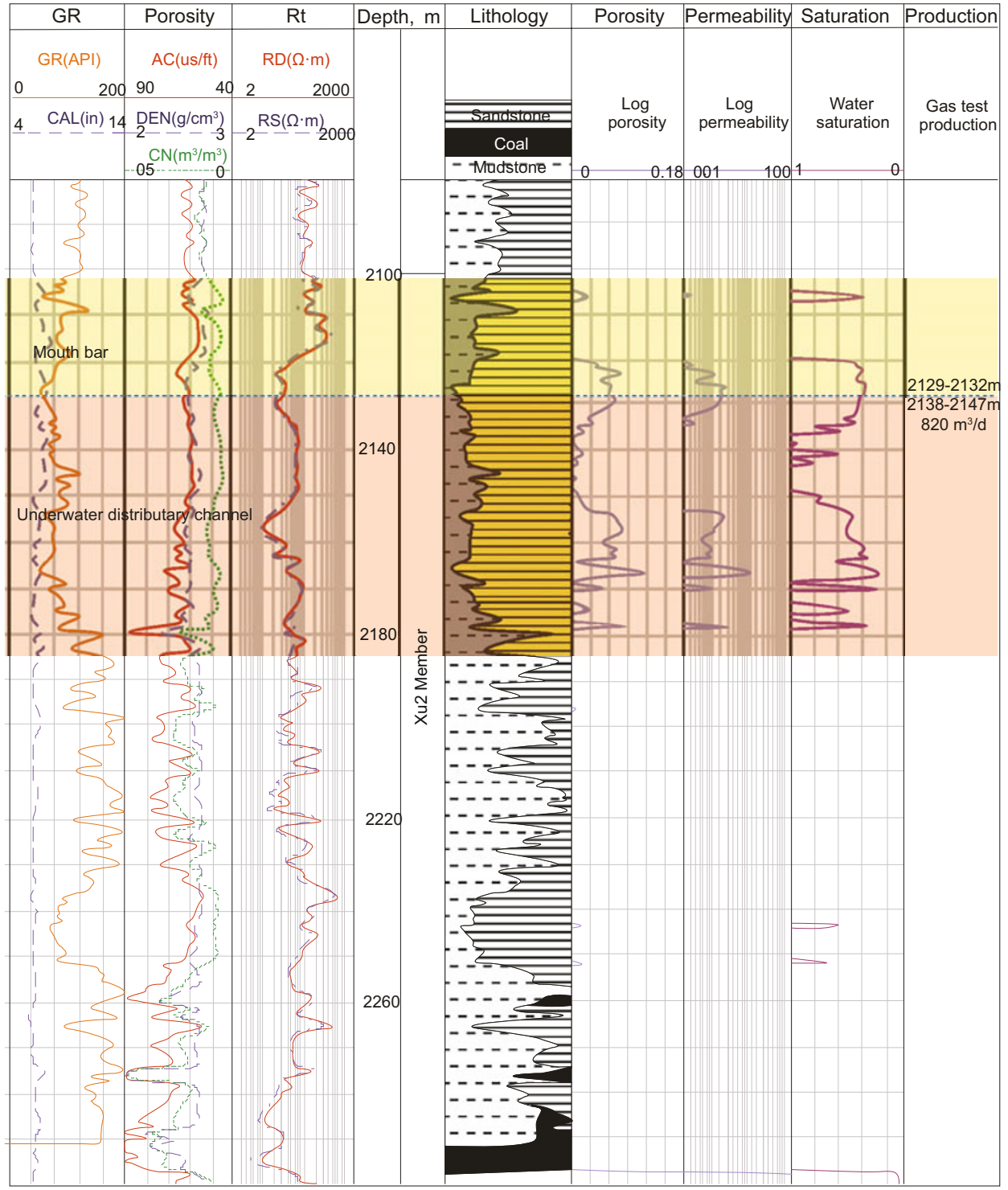

Fig. 13 Log curves of H105. 2110-2125 m: mouth bar, porosity 6\%, permeability $0.1 \mathrm{mD} ; 2125-2145 \mathrm{~m}$ : underwater distributary channel, porosity $7 \%$, permeability $0.15 \mathrm{mD}$

The experimental samples were 80-100 mesh glass beads (on behalf of conventional natural gas pools) and 250-300 mesh glass beads (on behalf of "continuous" tight gas reservoirs) (Table 5).

The physical simulation experiment was performed using equipment in the Key Laboratory of Petroleum Accumulation of CNPC. The whole equipment includes the increase extrusion system, the injection system, the "one-dimensional" model system, and the measurement system. The increase extrusion system is used to add the overburden pressure through the hydraulic pump or air pump; the injection system is used to charge gas, oil or water; the model system is used to perform the experiments, including the invisible tube glass model and the visible glass model; the measurement system is used to measure the flow of gas, oil and water (Fig. 18).

In the first set of experiment, we used the invisible tube glass model whose maximum overburden pressure is 40 $\mathrm{MPa}$. We measured the 80-100 mesh glass beads sample first and then the sample with the smaller 250-300 mesh beads. The specific steps were as follows. First, we filled the tube glass model with water, then filled it with the glass beads and ensured the water saturation was $100 \%$. Second, we added the simulated overburden pressure with the piston for 10 hours, and then recorded the experimental permeability and charge pressure data. Third, we injected natural gas into bottom of the model for 1 hour, measured the gas input and the water output, and calculated the experimental gas saturation of the model (equivalent to the overall gas saturation of the actual pool). The experimental data indicated that the overall gas saturation of the small beads sample (simulating a "continuous" natural gas reservoir) was higher than that of the large beads sample (simulating a conventional natural gas pool).

In the second set of experiment, we used visible glass model which cannot withstand the overburden pressure, but can be observed. Different from the first set of experiment, we measured two samples (80-100 mesh glass beads and 250300 mesh glass beads) at the same time for easy comparison. The specific steps were as follows. First, we filled the glass model with red ink, then filled it with beads and ensured the 

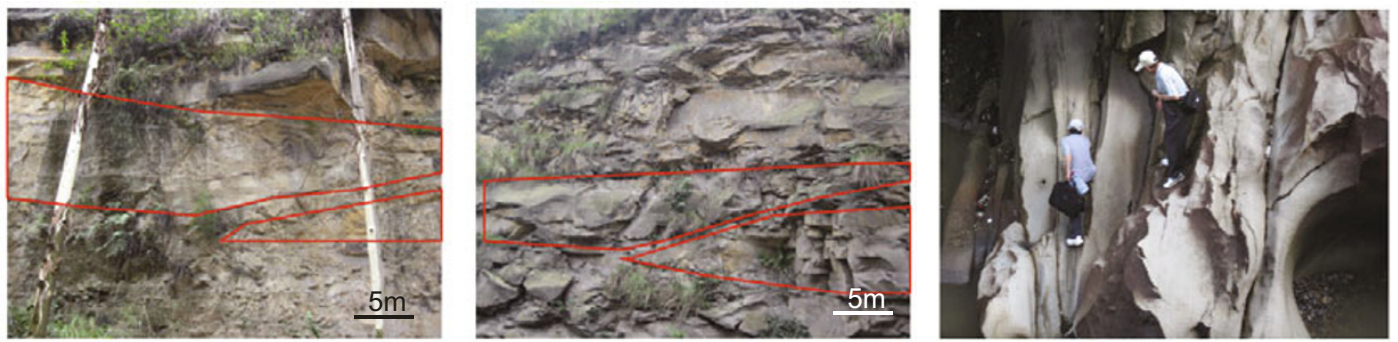

Fig. 14 Huangshiban Outcrop-1 of the Xu2 Member in Weiyuan area, the middle-south transition region

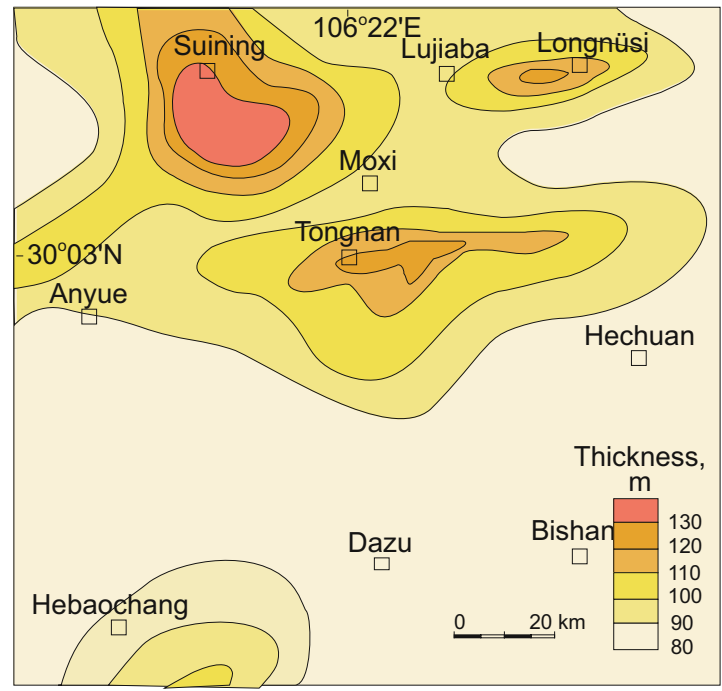

Fig. 15 Map of the thickness of reservoir rocks of the Xu2 Member in the study area

water saturation was $100 \%$. Second, we packed the glass beads for 10 hours, injected gas into the bottom of the model for 1 hour, and then observed the color change and the gas migration within the glass model. One hour after the gas injection, the migration process was completed. We found that the natural gas of "continuous" tight gas reservoirs (simulated by 250-300 mesh glass beads) moved up with no preferential petroleum migration pathways (PPMP) (Fig. 19(a)) at a rate of $0.3 \mathrm{~cm} / \mathrm{min}$ and the gas saturation was greater than $70 \%$. Comparatively, the natural gas in the 80-100 mesh glass beads (simulating a conventional natural gas pool) moved up with a fixed PPMP (6-7 cm wide) in the center of the column (Fig. 19(b)) at a rate of $0.8 \mathrm{~cm} / \mathrm{min}$ and the gas saturation was less than $30 \%$.

Because the permeability of the "continuous" natural gas reservoir model was much less than that of the conventional natural gas pool model, the gas moved up through the column much more slowly. However, all the small beads inside the column were a natural gas-saturated pathway, and the pores between the beads could capture the gas, which resulted in high gas saturation (70\%). Conversely, the accumulation of simulated conventional natural gas pool was controlled by the buoyancy. Once the PPMP was formed, the residual natural gas changed the wettability of the beads' surface. What is more, the PPMP was in fact the most conducive for migration, so the PPMP remained stable during the entire migration experiment.

Because the permeability of conventional gas pools

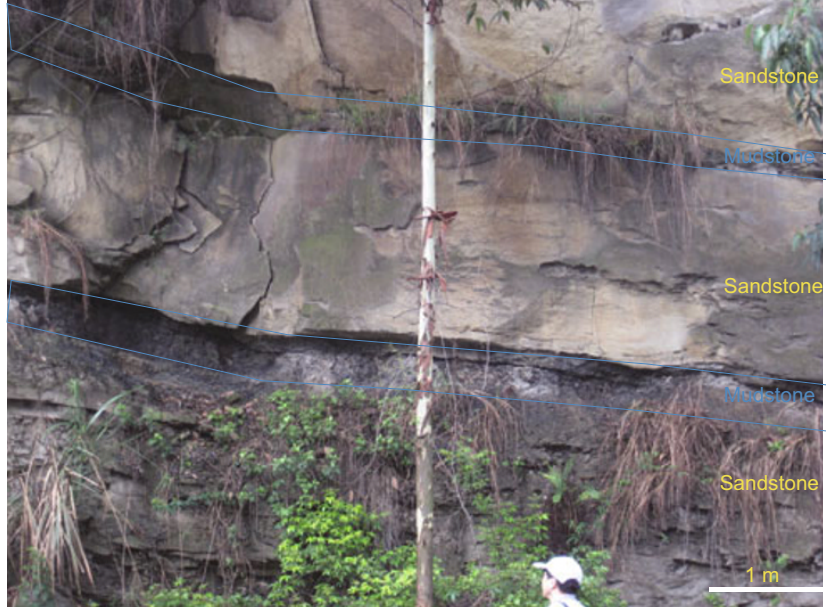

Fig. 16 Huangshiban Outcrop-2 of the Xu2 Member in Weiyuan area, the middle-south transition region

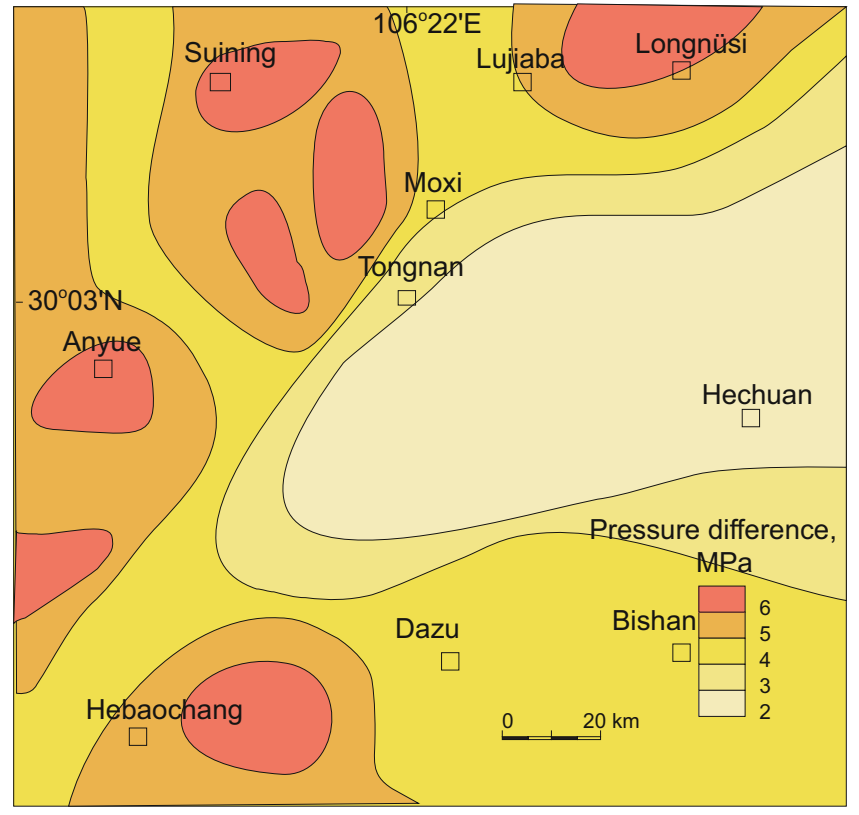

Fig. 17 Pressure in source rocks and reservoir rocks in the study area

was higher, the natural gas moved up much more quickly. However, only the pores of beads in the PPMP could capture the gas rather than the whole section, which resulted in a low gas saturation $(30 \%)$.

\section{Conclusions}

1) The reservoirs of the Xu2 Member in the middle-south transition region are typical "continuous" tight gas reservoirs. 
Table 5 Comparison of parameters of experimental sand and reservoir rocks in the Xu2 Member

\begin{tabular}{cccc}
\hline & $80-100$ mesh glass beads & 250-300 mesh glass beads & Reservoir rocks of Xu2 Member \\
\hline Density, g/cm & 1.6 & 1.6 & 1.02 \\
Porosity, $\%$ & 33.2 & 31.5 & 6.25 \\
Permeability, $\mathrm{mD}$ & 185.7 & 4.3 & 0.07 \\
Critical injection pressure, $\mathrm{MPa}$ & 0.01 & 0.03 & 3.5 \\
\hline
\end{tabular}

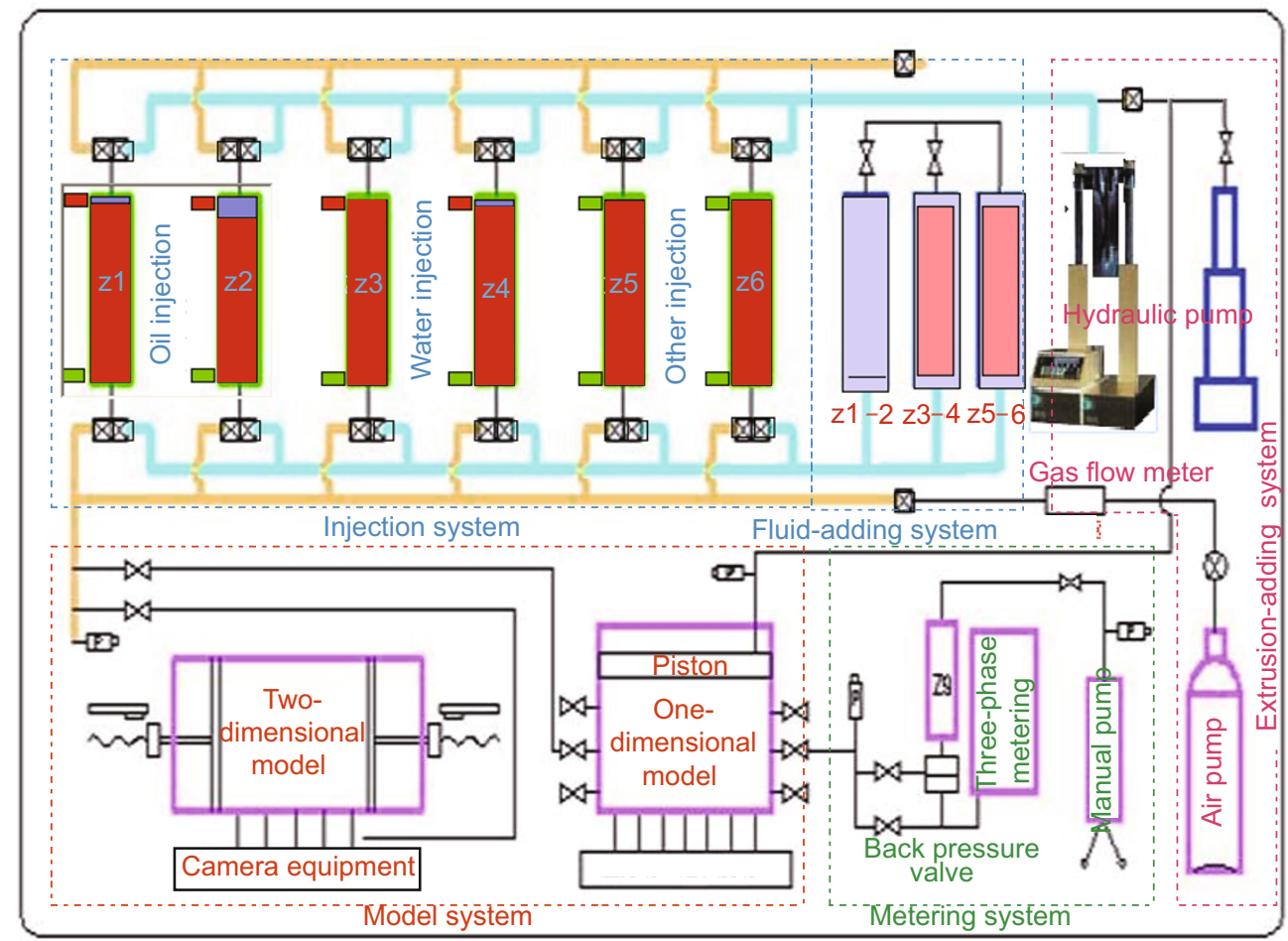

Fig. 18 Experimental flow chart

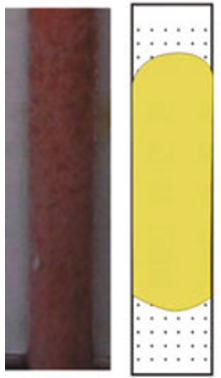

(a)

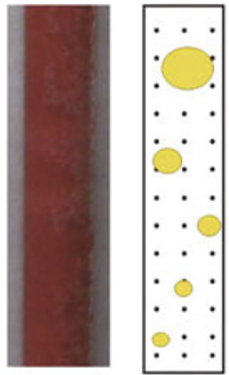

(b)
Fig. 19 Photos of the second set of experiment (one hour after gas injection). (a): "Continuous" tight gas reservoir, 250-300 mesh, no PPMP, pressure difference between source rocks and reservoir rocks is the driving force for the migration. (b): Conventional natural gas reservoir, 80-100 mesh, stable PPMP, the buoyancy is the driving force for the migration

Source rocks are primarily coals (average thickness is 2.5 $\mathrm{m}$ ) and mudstones (average thickness is $40 \mathrm{~m}$ ) of the $\mathrm{Xu} 1$ Member, and some mudstones of the Xu2 Member (average thickness is $12 \mathrm{~m}$ ). Source rocks primarily contain type III kerogen, and are distributed continuously in this study area. Peak gas generation is occurring at the present day because the maturity of the source rocks ranges from $1.0 \%$ to $1.5 \%$.
The high natural gas generation intensity (average $1,000 \times 10^{6}$ $\mathrm{m}^{3} / \mathrm{km}^{2}$ ) guarantees the formation of "continuous" natural gas reservoirs of the $\mathrm{Xu} 2 \mathrm{Member}$ in this area.

2) The reservoir rocks, primarily large sets of medium-fine sandstones (average thickness is $80 \mathrm{~m}$ ) of the Xu2 Member, are also thick and are distributed continuously in this study area. The average porosity of the Xu2 reservoir rocks is $5 \%$ to $6 \%$, and the logging Darcy permeability is less than 0.1 $\mathrm{mD}$. The sedimentary facies of the Xu2 Member are braided delta fronts in shallow lakes. Channels changed frequently during the deposition, resulting in interspersed distribution of large sets of sandstones and mudstones, which is helpful for forming "continuous" tight gas reservoirs. The low porosity, permeability and free water saturation of the reservoir rocks result in poor potential energy exchange between lower and upper natural gas layers, and the natural gas layers are thin, so the buoyancy is less than the capillary pressure, meaning that the buoyancy cannot provide enough driving force for gas migration. The gas accumulation of "continuous" tight gas reservoirs is controlled by an adequate driving force between the pressures in source rocks and reservoirs, which is demonstrated by a "one-dimensional" physical simulation experiment of "continuous" tight gas reservoirs. 


\section{Acknowledgements}

The study was supported by the National Major Grant of "Accumulation Law, Key Technologies and Evaluations of the Stratigraphic Reservoirs" (No. 2008ZX05000-001) from the Research Institute of Petroleum Exploration \& Development, PetroChina. We thank Yuan Xuanjun, Zhu Rukai, Hou Lianhua, Jia Jinhua, Guo Xiaowen, Ni Yunyan, Zhang Xiangxiang and Gao Xiaohui of RIPED for their support. As well, we would like to thank Zhang Shuichang, Song Yan, Zhao Mengjun and Jiang Lin of the CNPC Key Laboratory of Hydrocarbon Accumulation, and Xu Chunchun, Zhang Jian, Yang Guang, Yang Jiajing, Li Guohui and Wu Changjiang of Sichuan Oil Field Company for data and assistance during our study.

\section{References}

Cook T. Calculation of estimated ultimate recovery (EUR) for wells in assessment units of continuous hydrocarbon accumulations. Total Petroleum System and Assessment of Coalbed Gas in the Powder River Basin Province, Wyoming and Montana. U.S. Geological Survey Digital Data Series DDS-69-C. 2004. 1-6

Crovelli R A. Analytic resource assessment method for continuous-type petroleum accumulations-The ACCESS assessment method. Total Petroleum System and Assessment of Coalbed Gas in the Powder River Basin Province, Wyoming and Montana. U.S. Geological Survey Digital Data Series DDS-69-C. 2004. 1-12

Deng K L. The formation, evolution and petroleum exploration in Sichuan Basin. Natural Gas Industry. 1992. 12(5): 179-186 (in Chinese)

Gautier D L, Dolton G L, Takahashi K I, et al. National Assessment of United States Oil and Gas Resources-Results, Methodology, and Supporting Data. U.S. Geological Survey Digital Data Series DDS30. $1995.1-10$

Guo Z W, Deng K L, Han Y H, et al. The Formation and Evolution of the Sichuan Basin. Beijing: Geological Publishing House. 1996. 32 46 (in Chinese)

Huang S W, Zhang T S, Wang S Y, et al. Research on source characteristics and origin of Xujiahe Formation, upper Triassic in Chishui area, Sichuan Basin. Natural Gas Geoscience. 2004. 15(6): 590-592 (in Chinese)

Klett T R and Charpentier R R. FORSPAN Model Users Guide. U.S. Geological Survey Open-File Report 03-354. 2003. 1-35

Klett T R and Schmoker J W. U.S. Geological Survey Input-Data Form and Operational Procedure for the Assessment of Continuous Petroleum Accumulations: USGS Uinta-Piceance Assessment Team, Petroleum Systems and Geologic Assessment of Oil and Gas in the Uinta-Piceance Province, Utah and Colorado. U.S. Geological Survey Digital Data Series DDS-69-B. 2004. 1-9

Li Y H, Shi X R, Yang X N, et al. Reservoir conditions of the Upper Triassic in central-western Sichuan Basin. Natural Gas Exploration \& Development. 2003. 26(3): 1-6 (in Chinese)

Long S X, Huang R C, Li H T, et al. Formation mechanism of the Changxing Formation gas reservoir in the Yuanba Gas Field, Sichuan Basin, China. Acta Geologica Sinica. 2011. 85(1): 233-242

Luo Z L and Tong C G. Plate Tectonics and Chinese Oil and Gas Basins. Wuhan: China University of Geosciences Press. 1989. 6-14 (in Chinese)

Pollastro R M. Total petroleum system assessment of undiscovered resources in the giant Barnett Shale continuous (unconventional) gas accumulation, FortWorth Basin, Texas. AAPG Bulletin. 2007. 91(4): $551-578$
Schmoker J W. U.S. Geological survey assessment model for continuous (unconventional) oil and gas accumulations-the "FORSPAN" model. U.S. Geological Survey Bulletin. 1999. 2168(9)

Schmoker J W. Resource-assessment perspectives for unconventional gas systems. AAPG Bulletin. 2002. 86(11): 1993-2000

Schmoker J W. U.S. geological survey assessment concepts for continuous petroleum accumulations. U.S. Geological Survey Digital Data Series DDS-69-D. 2005. 1-9

Wang D Y, Zeng H S and Wang J Y. Evaluation on upper Triassic hydrocarbon source rocks of western Sichuan Depression, Sichuan Basin. Petroleum Geology \& Experiment. 2010. 32(2): 192-195 (in Chinese)

Wang M, Li X Q, Huang X B, et al. Characteristics of fluid inclusions and hydrocarbon accumulation period of natural gas of Xujiahe Formation in Hechuan large gas-field. Journal of Oil and Gas Technology. 2012. 34(12): 18-23 (in Chinese)

Wang N, Chen B N and Zhai J F. Reservoir forming index for the lithological oil reservoir. Petroleum Exploration \& Development. 2000. 27(6): 4-9 (in Chinese)

Wang S Q, Luo Q H and Wu D M. Organic petrology of source rocks from the upper Triassic coal measures in the central and western Sichuan Basin. Journal of Mineralogy and Petrology. 1997. 17(1): 63-70 (in Chinese)

Wang Z C, Zhao W Z, Zhang L, et al. The Tectonic Sequence and Gas Exploration in Sichuan Basin. Beijing: Geological Publishing House. 2002. 3-7 (in Chinese)

Yang X P, Zou C N, Li W, et al. The characteristics and the evolution of the diagenetic porosity in the oil-gas reservoir of the Upper Triassic Xiangxi Formation in the central Sichuan Basin. Bulletin of Mineralogy, Petrology and Geochemistry. 2006. 25(1): 55-59 (in Chinese)

Zhang $\mathrm{J}$ and Zhang Q. The history and prospects of oil and gas exploration in Sichuan Basin. Natural Gas Industry. 2002. 22(S1): 3-7 (in Chinese)

Zhang X X, Zou C N, Tao S Z, et al. Diagenetic facies types and semi quantitative evaluation of low porosity and permeability sandstones of the fourth member Xujiahe Formation Guangan area, Sichuan Basin. Acta Sedimentologica Sinica. 2010. 28(1): 50-57 (in Chinese)

Zhang Y B, Jia C Z, Zhao Z J, et al. Characteristics of Milankovitch cycles in the Mid-Permian Liangshan and Qixia Formations of the Sichuan Basin-Examples from Well-Long17 and Well-Wujia1. Acta Geologica Sinica. 2012. 86(5): 1045-1059

Zhao W Z, Wang Z C, Wang H J, et al. Principal characteristics and forming conditions for medium-low abundance large scale oil/gas fields in China. Petroleum Exploration and Development. 2008. 35(6): 641-650 (in Chinese)

Zhu R K, Zhao X, Liu L H, et al. Depositional system and favorable reservoir distribution of Xujiahe Formation in Sichuan Basin. Petroleum Exploration and Development. 2009. 36(1): 46-55 (in Chinese)

Zou C N, Tao S Z, Yuan X J, et al. Global importance of "continuous" petroleum reservoirs: Accumulation, distribution and evaluation. Petroleum Exploration and Development. 2009a. 36(6): 669-681 (in Chinese)

Zou C N, Tao S Z, Zhu R K, et al. Formation and distribution of "continuous" gas reservoirs and their giant gas province: A case from the Upper Triassic Xujiahe Formation giant gas province, Sichuan Basin. Petroleum Exploration and Development. 2009b. 36(3): $307-$ 319 (in Chinese)

Zou C N, Zhao W Z, Zhang X Y, et al. Formation and distribution of shallow-water deltas and central-basin sand bodies in large open depression lake basins. Acta Geologica Sinica. 2008. 82(6): 813-825 (in Chinese)

(Edited by Hao Jie) 